\title{
Frozen spin targets developed at Dubna. History and traditions
}

\author{
Yu.A. Usov* \\ Joint Institute for Nuclear Research, \\ 141980 Dubna, Russia \\ E-mail: vuusovdjinr.rul
}

\begin{abstract}
A frozen spin polarized targets cooled by the ${ }^{3} \mathrm{He} /{ }^{4} \mathrm{He}$ dilution refrigerator developed at the JINR, Dubna is described. Experience with continuously-polarized targets (dynamic mode) and achieving of very low temperatures in 1966 (JINR) gave rise to the idea of using radically new technique based on dissolving ${ }^{3} \mathrm{He}$ in ${ }^{4} \mathrm{He}$ to the frozen spin polarized target. The short history (1976-2015) of the development of such proton and deuteron targets at JINR for different accelerators (Dubna, Protvino, Gatchina, Prague and Mainz) is given.
\end{abstract}

XVIth International Workshop in Polarized Sources, Targets, and Polarimetry, PSTP2015,

14-18 September 2015,

Bochum, Germany

\footnotetext{
* Speaker.
} 
Polarized LMN target development started at Dubna in 1964 when Chamberlain supplied the exact prescription for crystal production. The target prepared by V. Luschikov, B. Neganov, L. Parfenov and Yu. Taran [W] first was used for pp-scattering at $660 \mathrm{MeV}$ at the Dubna synchrocyclotron. Before, V. Luschikov and Yu. Taran visited the Anatole Abraham Laboratory to get the experience in NMR technique.

Experience with polarized dynamic targets and achieving very low stationary temperatures in 1966 at JINR by B.S. Neganov, N.S. Borisov and M.Yu. Liburg [[]] and another group gave rise to the idea of using radically new technique based on dissolving ${ }^{3} \mathrm{He}$ in ${ }^{4} \mathrm{He}$ to the frozen spin polarized target [3]. In fact, four facilities of this type were developed [团] which are used until now in the experiments with the beams of IHEP-Protvino, PNPI-Gatchina, Charles UniversityPrague and Mainz University. The short history (1976-2015) of the development of such proton and deuteron targets at JINR is given.

The next target with a length of $20 \mathrm{~cm}$ and $60 \mathrm{~cm}^{3}$ in volume which has been used for experiments with $40 \mathrm{GeV} \pi^{-}$mesons and $70 \mathrm{GeV}$ protons at the accelerator of the Institute of High Energy Physics (Protvino) since 1978 [[]]. A lot of articles (over 40) were published since 1976 using these two targets. In 1988 this frozen target was upgraded to the deuteron mode [ 6 ].

In 1994 we have developed the new target $20 \mathrm{~cm}^{3}$ in volume intended for polarization parameter studies in np-scattering using a $15 \mathrm{MeV}$ polarized neutron beam produced by the Van de Graaf accelerator of the Charles University, Prague $[\mathbb{[}]$. This target is a complex including a stationary cryostat with a dilution refrigerator, a movable magnetic system providing a "warm" field and consists of a superconducting dipole magnet with a large aperture and electronic equipment for providing dynamic polarization and NMR-signal detection. The further development of this target is under preparation for deuteron polarization for next experiments. The purpose of this project is to study three-nucleon interactions using a $14-16 \mathrm{MeV}$ polarized neutron beam in a conjunction with the polarized deuteron target.

The last development is the reconstruction of the Saclay-Argonne frozen spin proton polarized target which was built for and used initially in experiments at FermiLab [ [ $]$. A new quality was given to the target during this reconstruction - transportability from one experimental area to another. All the major parts of the target assembly disposed closely to the beam line are mounted on two separate decks, which can be moved as blocks in and out of the beam, and also between various accelerators.

The new frozen spin polarized target has been developed together with the group from Mainz University for experiments with the polarized beam of the "real" photons at the A2 facility of the "MAMI" accelerator to measure the photon absorption cross section at energies up to $1.5 \mathrm{GeV}$ [Q].

\section{As a resume:}

London, Clarke and Mendoza proposed a continuously working refrigerator based on the principle of dilution of ${ }^{3} \mathrm{He}$ in ${ }^{4} \mathrm{He}$ (Phys. Rev. 128 (1962) 1992). This paper was brought to Dubna by S. Šafrata [10]].

\section{The first realizations were:}

1) B.S. Neganov, N.S. Borisov and M.Yu. Liburg, "Zh. Exp. Teor. Fiz." 50 (1966) 1445.

Tmin=50 $\mathbf{m K}$. 
2) H.E. Hall, P.J. Ford and K. Thomson, :Cryogenic" 6 (1966) 80.

\section{Tmin=200 $\mathbf{~ m K}$.}

3) P. Das, R. de Bryan Outboter and K.W. Taconis, LT9, 1965, pp. 1253-1255.

\section{Tmin=220 $\mathbf{m K}$.}

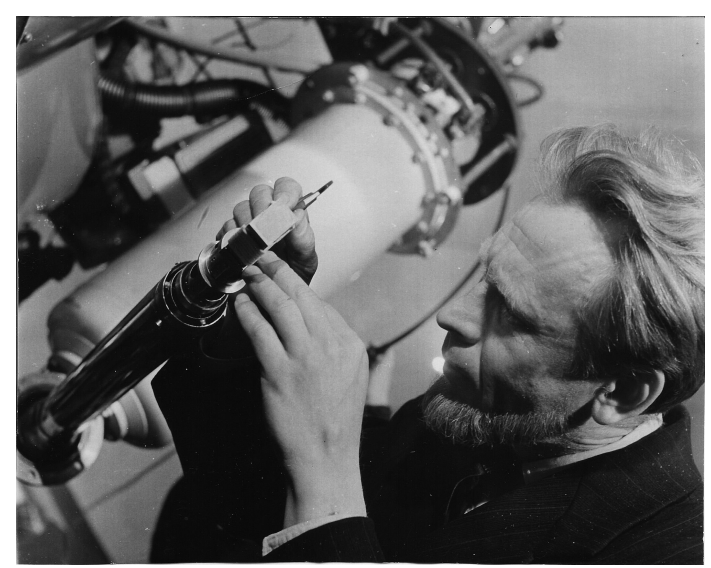

Figure 1: B.S. Neganov during tuning of the $1 \mathrm{~K}$ dinamic polarized target (DPT) (approx. 1965).

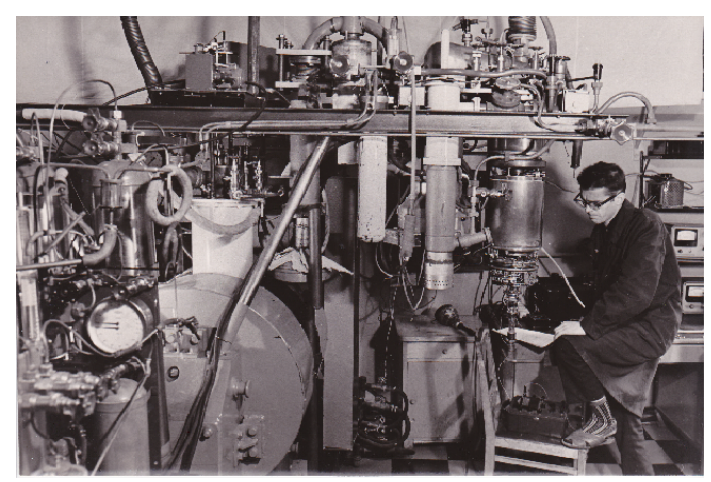

Figure 3: A combine setup including the $1 \mathrm{~K}$ DPT and the dilution refrigerator in which ultra low temperature $5.5 \mathrm{mK}$ was reached (N.S. Borisov).

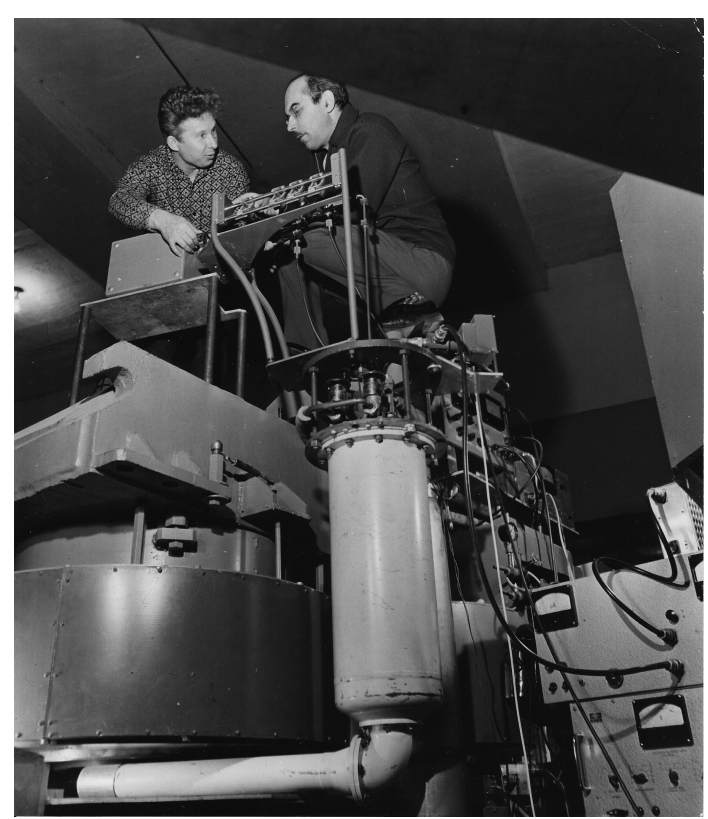

Figure 2: The $1 \mathrm{~K} \mathrm{DPT}$ at beam area (right L. Parfenov).

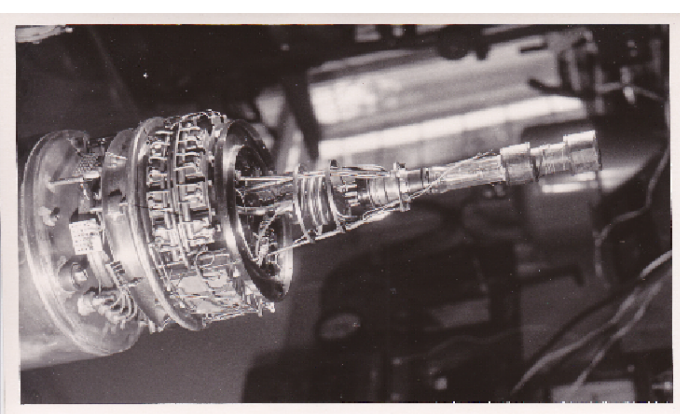

Figure 4: An ultra low part of the cryostat of the dilution refrigerator (approx. 1966). 


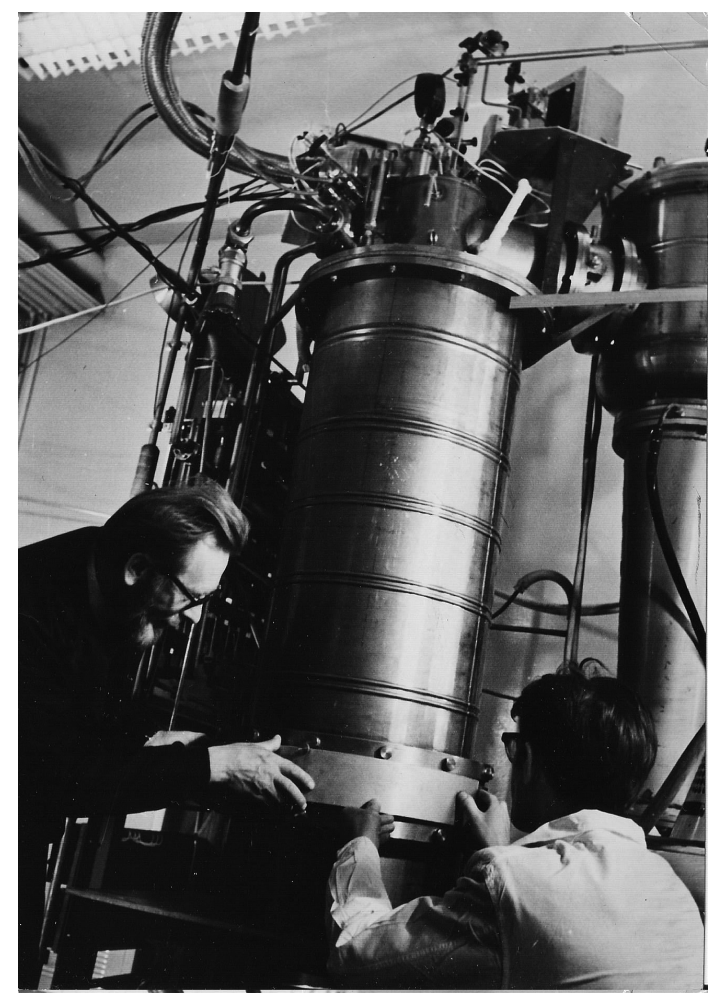

Figure 5: The first frozen spin target (FST) during test preparation (1975).

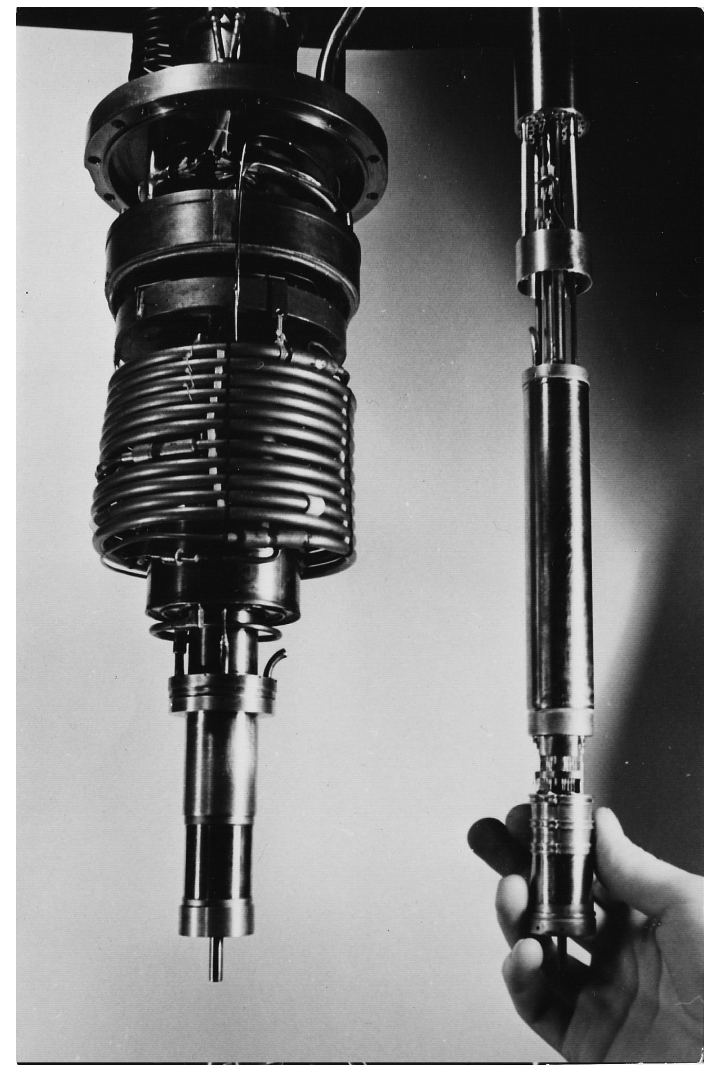

Figure 6: The low temperature unit of the FST and insert for loading target material.

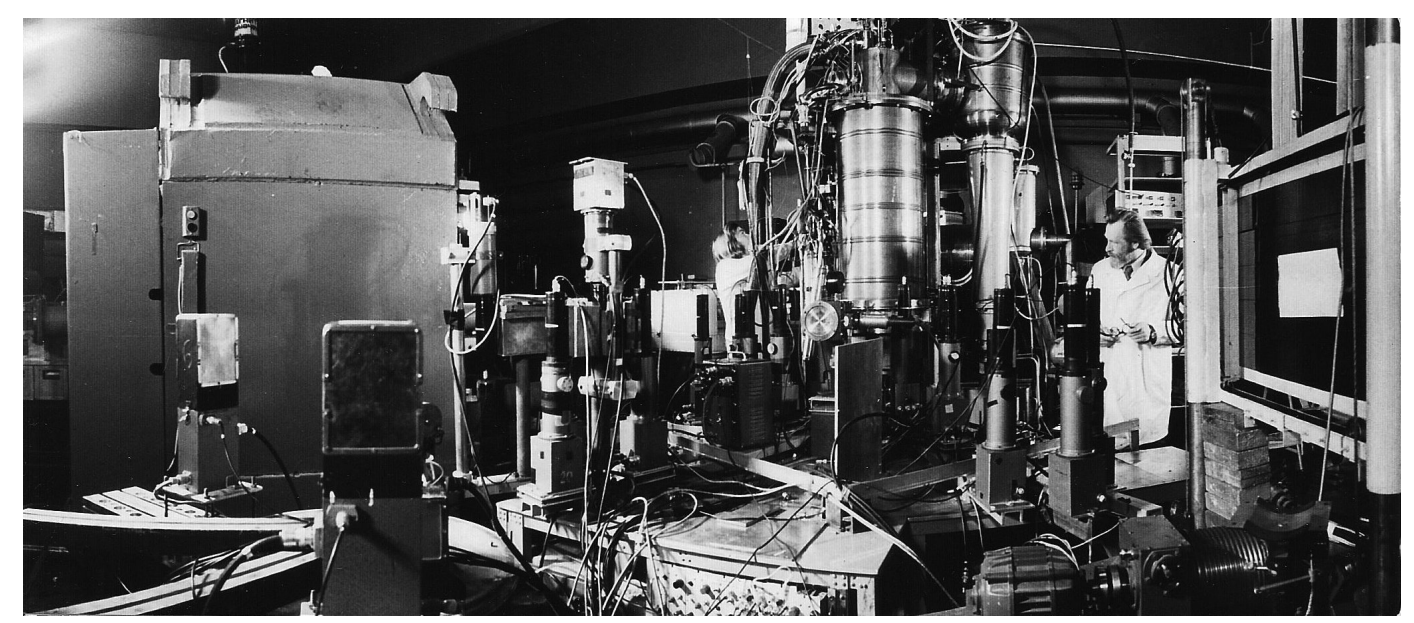

Figure 7: The first FST during the experiment " $\pi \mathrm{p} "$ at the Dubna Phasotron (1975). 


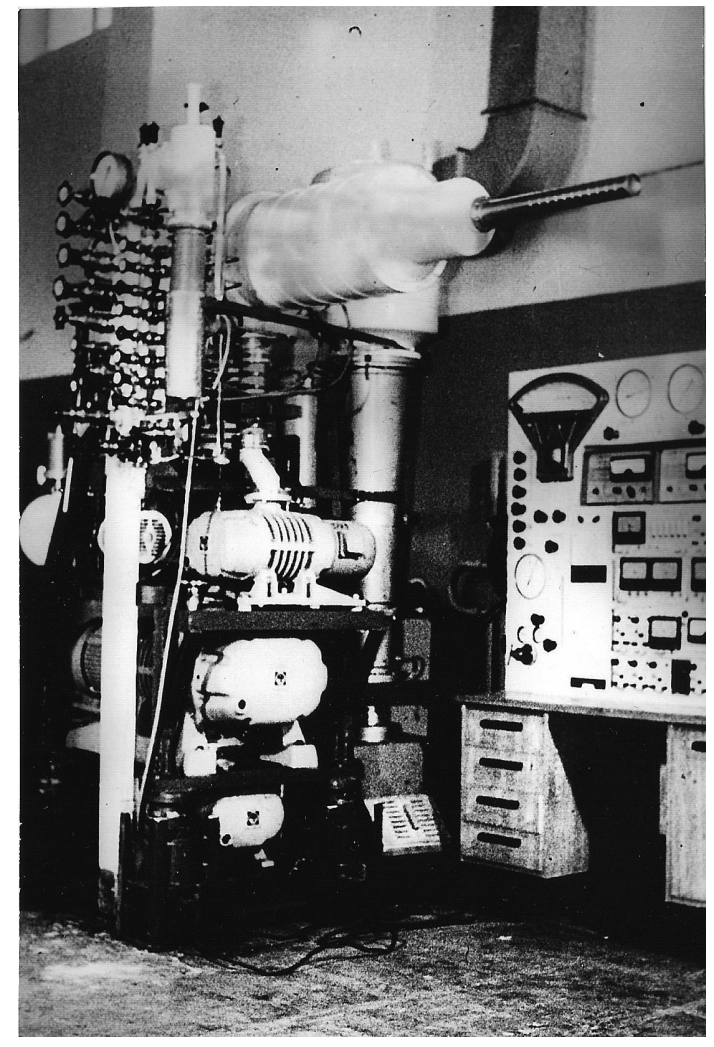

Figure 8: The second FST before transportation from Dubna to IHEP (Protvino) (1978)

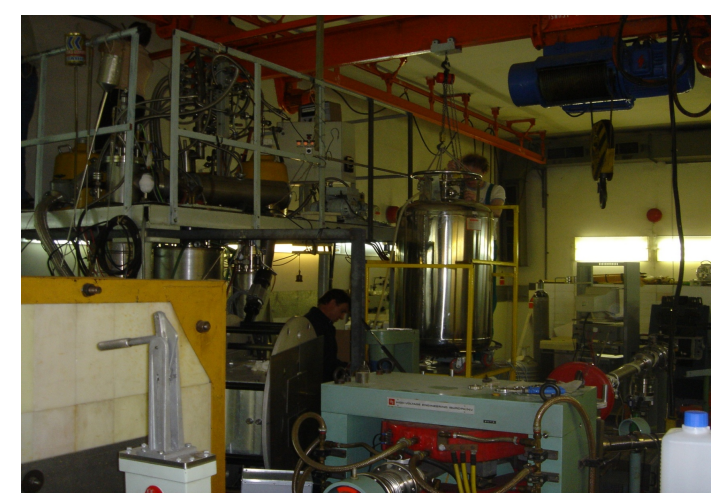

Figure 10: The FST for experiments at low energies (Prague).

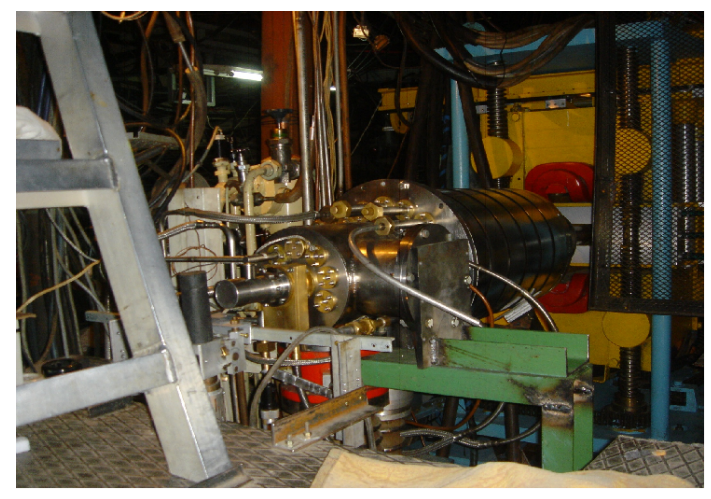

Figure 9: The Second FST at beam area.

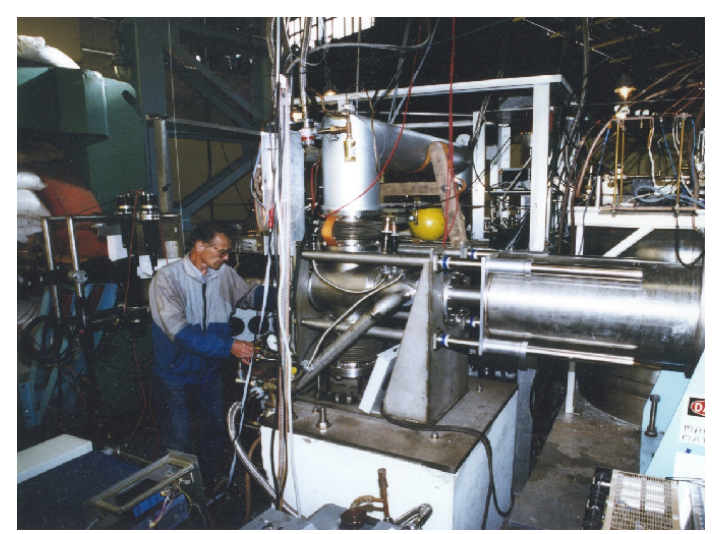

Figure 11: The movable FST for high energy spin physics experiments (Dubna-Nuclotron). This project was supported with INTAS grants in 1993 and 1995. 


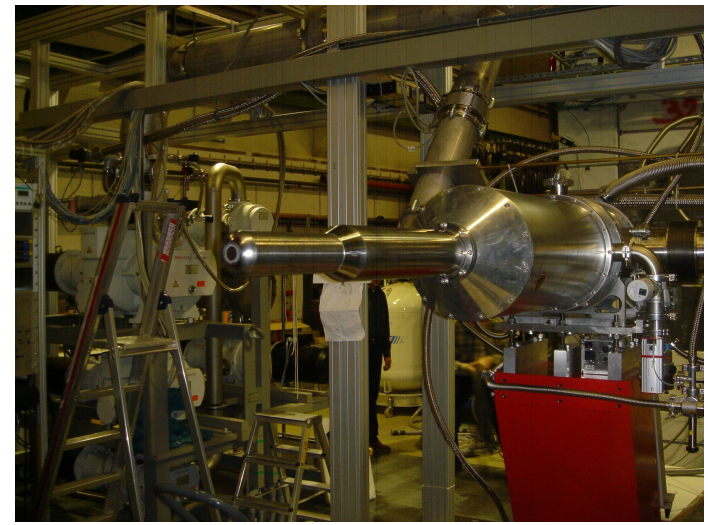

Figure 12: The FST of "MAMI C" (Mainz).

\begin{tabular}{|c|c|c|c|c|c|c|}
\hline $\begin{array}{l}\text { Year } \\
\text { of } \\
\text { first } \\
\text { publ. }\end{array}$ & $\begin{array}{c}\text { Volume } \\
\mathrm{cm}^{3}\end{array}$ & Material & $\begin{array}{c}\text { Magnetic } \\
\text { field, } T \\
\text { dynamic/ } \\
\text { frozen mode }\end{array}$ & \begin{tabular}{|c|} 
Accelerator \\
(place)
\end{tabular} & $\begin{array}{c}\text { Maximum } \\
\text { polarization, \%, }\end{array}$ & $\begin{array}{c}\text { Tmin, } \\
\mathrm{mK}\end{array}$ \\
\hline 1976 & 15 & $\begin{array}{c}\mathrm{C}_{3} \mathrm{H}_{6}(\mathrm{OH})_{2} 1,2- \\
\text { propanediol } \\
\text { with } \mathrm{Cr}(\mathrm{V})\end{array}$ & $2.69 / 2.69$ & $\begin{array}{c}\text { Dubna, } \\
\text { Gatchina } \\
\text { (in use) }\end{array}$ & $P_{ \pm}=98 \pm 2$ & 36 \\
\hline 1980 & 60 & $\begin{array}{c}\mathrm{C}_{3} \mathrm{H}_{6}(\mathrm{OH})_{2} 1,2- \\
\text { propanediol } \\
\text { with } \mathrm{Cr}(\mathrm{V})\end{array}$ & $2.06 / 0.45$ & $\begin{array}{c}\text { Protvino } \\
\text { (in use) }\end{array}$ & $P_{ \pm}=87 \pm 3$ & 20 \\
\hline 1985 & 60 & $\begin{array}{l}\left(\mathrm{CD}_{2} \mathrm{OD}\right)_{2} \\
\text { deuterated } \\
\text { ethanediol } \\
\text { with } \mathrm{Cr}(\mathrm{V})\end{array}$ & $2.06 / 0.45$ & $\begin{array}{r}\text { Protvino } \\
\text { (in use) }\end{array}$ & $P_{ \pm}=37 \pm 3$ & \\
\hline 1994 & 20 & $\begin{array}{c}\mathrm{C}_{3} \mathrm{H}_{6}(\mathrm{OH})_{2} 1,2- \\
\text { propanediol } \\
\text { with } \mathrm{Cr}(\mathrm{V})\end{array}$ & $2.7 / 0.37$ & $\begin{array}{l}\text { Prague } \\
\text { (in use) }\end{array}$ & $\begin{array}{l}P_{+}=93 \pm 3 \\
P_{-}=98 \pm 2\end{array}$ & 20 \\
\hline 1995 & 140 & $\begin{array}{c}\mathrm{C}_{3} \mathrm{H}_{6}(\mathrm{OH})_{2} 1,2- \\
\text { propanediol } \\
\text { with } \mathrm{Cr}(\mathrm{V})\end{array}$ & $2.7 / 2.7$ & $\begin{array}{l}\text { Dubna } \\
\text { (in use) }\end{array}$ & $\begin{array}{l}P_{+}=84 \pm 3 \\
P_{-}=91 \pm 3\end{array}$ & 50 \\
\hline 2013 & 10 & $\begin{array}{c}\mathrm{H} / \mathrm{D} \\
\text { butanol }\end{array}$ & $2.5 / 0.5$ & $\begin{array}{l}\text { Mainz } \\
\text { (in use) }\end{array}$ & $P_{H / D}=85 / 75$ & 25 \\
\hline
\end{tabular}

Figure 14: Parameters of the frozen spin targets of JINR

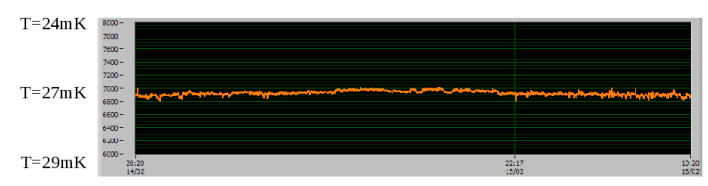

Figure 13: Temperature stability $\Delta T \approx \pm 0.2 \mathrm{mK}$ (one day), typical one week measurement period.

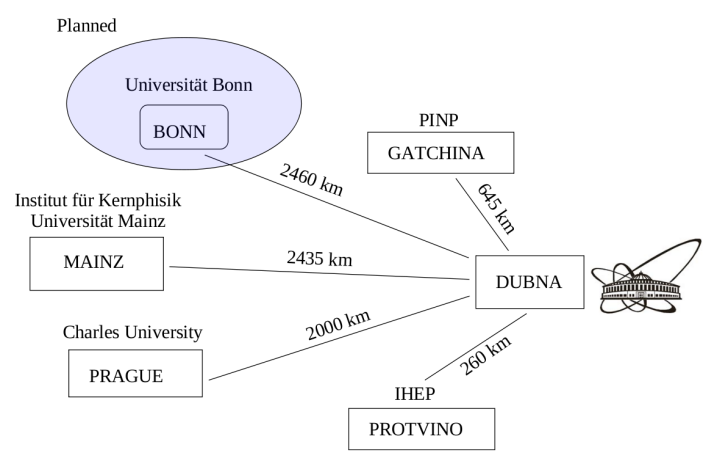

Figure 15: The map of JINR's frozen spin target activities).

\section{References}

[1] V.I. Luschikov, B.S. Neganov, L.B. Parfenov and Yu.V. Taran, Sov. Phys. JETP 22 (1966) 285.

[2] B.S. Neganov, N.S. Borisov, M.Yu. Liburg, JETP 50 (1966) 1445.

[3] N.S. Borisov et al., JINR Preprints 13-10253, 10-10257, Dubna 1976; Prib. Techn. Exp. 2 (1978) 32.

[4] Yu.A. Usov, Nucl. Instr. \& Meth. A 526 (2004) 153.

[5] N.S. Borisov et al., JINR Communication 1-80-98, Dubna 1980.

[6] N.S. Borisov et al., J. Phys. E: Sci.Instrum. 21 (1988) 1179.

[7] N.S. Borisov et al., Nucl. Instr. \& Meth. A 345 (1994) 421.

[8] N.A. Bazhanov et al., Nucl. Instr. \& Meth. A372 (1996) 349.

[9] A. Thomas et al., ISSN 1063-7796, Physics of Particles and Nuclei, 2013, Vol. 44, No. 6, pp. 964-967, Pleades Publishing, Ltd, 2013.

[10] S. Šafrata, Čs. Čas Phys. A19 (1968) 489. 